\title{
Status quo of adoption of precision agriculture enabling technologies in Swiss plant production
}

\author{
Tanja Groher ${ }^{1} \cdot$ Katja Heitkämper ${ }^{1} \cdot$ Achim Walter $^{2} \cdot$ Frank Liebisch $^{2,3}$. \\ Christina Umstätter ${ }^{1}$
}

Published online: 8 May 2020

(C) The Author(s) 2020

\begin{abstract}
This paper presents the state of application of Precision Agricultural enabling Technology (PAT) in Swiss farms as an example for small-scale, highly mechanised Central European agriculture. Furthermore, correlations between farm and farmers' characteristics and technology adoption were evaluated. Being part of a comprehensive and representative study assessing the state of mechanisation and automation in Swiss agriculture, this paper focuses on the adoption of Driver Assistance Systems (DAS) and activities in which Electronic Measuring Systems (EMS) are used. The adoption rate of DAS was markedly higher compared to EMS in all agricultural enterprises. The adoption rate was highest for highvalue enterprise vegetables and surprisingly low for the high-value enterprise grapes. The results of a binary logistic regression showed that farmers located in the mountain zone were less likely to adopt PAT compared to farmers in the valley. Small farm size correlated with low adoption rates and vice versa showing adoption happens country-specific in the upper farm size distribution. The results show the potential for novel technologies to be adopted by farmers of high-value products. Furthermore, technologies have been partially used to reduce physical workload but not yet to evaluate crop or management performance to support decisions. However, automatic collection and forwarding of data is a fundamental step towards Smart Farming realizing its full potential in the future.
\end{abstract}

Keywords Digitalisation · Precision agriculture $\cdot$ Technology uptake $\cdot$ Drivers of adoption

\section{Introduction}

The application and connection of digital technologies in agricultural production has been the focus of research and received increasing attention in the last years. The adoption of digital technologies in the agricultural sector comprises the use of electronic devices,

Tanja Groher

tanja.groher@agroscope.admin.ch

1 Agroscope, Competitiveness and System Evaluation, Tänikon 1, 8356 Ettenhausen, Switzerland

2 Institute of Agricultural Sciences, ETH Zurich, 8092 Zurich, Switzerland

3 Agroscope, Agroecology and Environment, 8046 Zurich, Switzerland 
robots, sensor technology and automation as well as the use of information and communication technologies. It is associated by terms such as Precision Agriculture (PA), Precision Farming (PF), Smart Farming, Digital Farming or Agriculture 4.0 (Paustian and Theuvsen 2017; Pierpaoli et al. 2013). Thereby, the aim of all these applications is to simplify and automate processes, reduce or even shift daily workloads from physical to cognitive labor and increase profitability while decreasing the ecological footprint of farming resulting in an integrated, improved and sustainable farm and decision management (Walter et al. 2017; Shepherd et al. 2018; Tey and Brindal 2012).

At the international level, there has been no consistent definition of PA for a long time (Lowenberg-DeBoer and Erickson 2019). A recently published definition of the International Society of Precision Agriculture states: "Precision Agriculture is a management strategy that gathers, processes and analyzes temporal, spatial and individual data and combines it with other information to support management decisions according to estimated variability for improved resource use efficiency, productivity, quality, profitability and sustainability of agricultural production." (ISPA 2019). The broadness of the definition considers PA at the management level and might make it difficult in some cases to define specific technologies inside or outside the PA category.

Therefore in the context of this paper, technologies related to plant production are summarized as precision agricultural enabling technologies (PAT), including the use of driver assistance systems (DAS) and electronic measuring systems (EMS). DAS comprises various support technologies and steering assistance technologies that relieve farmers of physical work-load or time spent in field and crop management and simplify processes from the perspective of labor economics (for example automatic steering systems). Such support technologies were considered in this study, as they are often considered as transition technologies and help making management more precise. Less additional training is needed for their application (Miller et al. 2019) and those technologies are comparable with guidance technologies in other studies (Miller et al. 2019; Schimmelpfennig 2018). The use of these systems is often but not necessarily based on global navigation satellite systems (GNSS) such as the global positioning system (GPS) which is the basis to reach the full optimization potential. The application of EMS is a more integrated use of PA and combines the use of GNSS, field or plant related sensors with farm machinery ready for real-time adjustments to the respective field or crop management. An example is the use of precision fertilization in which sensors based on, for example canopy reflection or chlorophyll fluorescence are installed at the machine, provide crop-nitrogen-status related indices and allows the inference of a nitrogen application rate (Heege 2013). However, PAT does not always have to comprise complex, expensive technologies. Even simple, cost-effective technologies, such as chlorophyll meters (Cao et al. 2012) or smartphone-based technologies (Pongnumkul et al. 2015) can provide useful information and help to make management decisions related to daily work. Reducing the input of $\mathrm{N}$ or pesticides is an important aim when promoting further use of PAT in the interest of sustainable agricultural practices (Gebbers and Adamchuk 2010).

Most available studies focus on the benefits and adoption of PA, which aim at the optimized handling of variability and uncertainties within agricultural fields by using sensors, enhanced machinery and information systems (Gebbers and Adamchuk 2010; Pierpaoli et al. 2013; Zhang et al. 2002). However, there are also difficulties arising from PAT adoption for farmers. The purchase of new technologies can be capital-intensive without taking a real cost/-benefit analysis into account (Lawson et al. 2011). Moreover, data interpretation, data rights and the compatibility of different manufacturers and, of course, farmers' personal interests and knowledge can be barriers in the adoption of new technologies 
(Reichardt and Jürgens 2009; Zhang et al. 2002; Batte and Arnholt 2003; Barnes et al. 2019).

Even if the application of PAT could offer many advantages for farmers, adoption in Europe has been little-studied so far (Barnes et al. 2019). According to Reichardt and Jürgens (2009) the adoption of PA was about $11 \%$ for German crop farmers in 2006. Eight years later Paustian and Theuvsen ( 2017) found a PA adoption rate of $30 \%$ for German farmers in 2014. In both studies, farmers were asked if they use PA without differentiating between possible technologies. This makes a comparison of adoption rates for specific technologies difficult. Some studies asked the farmers directly if they were PA users without asking which kind of technology or sensors they used, while other studies asked specifically about the applications of a certain technology and defined the farmers who used them as adopters. Thus, the different definitions of technologies as well as the data collection methods make it difficult to compare country adoption rates (Lowenberg-DeBoer and Erickson 2019).

Factors influencing the adoption rates depend on the type of technology investigated. For example, the adoption of nutrient-loss-reducing technologies as well as its influencing factors varied for spreading equipment, slurry tanks and precision technology (Konrad et al. 2019). Further, in a recent study by Barnes et al. (2019), the adoption of machine guidance (MG) and variable-rate nitrogen technologies (VRNT) (corresponding to DAS and EMS in this study) was studied among European Union farmers. The results showed that, respectively, $21 \%$ and $2 \%$ of the surveyed Belgian farmers, $36 \%$ and $14 \%$ of Greek farmers, $30 \%$ and $47 \%$ UK farmers, $34 \%$ and $26 \%$ of German farmers and $48 \%$ and $24 \%$ of Dutch farmers used MG and VRNT (Barnes et al. 2019). Thus, the results differed with regard to adoption and to influencing factors between the use of MG and VRNT. MG could also be described as an assistance tool, and VRNT combines a diagnostic tool (sensor) with a real-time adjusting device or equipment as applicative tools. Whereas diagnostic tools utilise different techniques to collect information, with the use of applicative tools management decisions can be made (Finger et al. 2019; McBride and Daberkow 2003).

Several studies have investigated potential drivers for the adoption of PAT, including farm and farmers' characteristics. Operator age is one example of a farmer' characteristic that may be an influencing factor in the adoption process. However, the results from the literature are inconsistent (Tey and Brindal 2012). Whereas some studies state that adopters are significantly younger compared to non-adopters (Barnes et al. 2019; Daberkow and McBride 2003), others could not find clear differences in age between the two groups but reporting that experience in crop farming of less than 5 years and more than 16 years increased the likelihood of adoption (Paustian and Theuvsen 2017). In addition, other correlated variables are known, such as region or full- or part-time farming (Reichardt and Jürgens 2009; Konrad et al. 2019). An example for a farm characteristic that often correlates with PAT adoption is farm size, mainly expressed in hectares of agricultural area. Farmers with larger farm sizes are often more likely to adopt technology (Konrad et al. 2019; Reichardt and Jürgens 2009; Tamirat et al. 2018). Several other farm characteristics are described in the literature such as number of livestock units, organic or conventional farming and farm or crop specialization (Konrad et al. 2019; Paustian and Theuvsen 2017). However, it is important to note that these studies are not based on representative sampling procedures in terms of region, farm size or farm type, which would allow for generalization of results. These are rather exemplary studies, which, however, cannot be applied to other technologies or other countries.

Structural change in agriculture has also had an impact on Switzerland. But despite an average increase in farm size and specialization, Switzerland's agricultural landscape is 
still more diverse compared to other European countries. In 2018, the average farm size in Switzerland was about 20.5 ha which is almost half the size of farms in Germany or France (Ferjani et al. 2015; FOAG 2018). These structures are reinforced by strong financial support from the federal government to promote sustainable agriculture including, for example, the maintenance of the cultural landscape or ensuring animal welfare (Pierpaoli et al. 2013; FSO 2018a). However, structural change has also taken place in Switzerland albeit to a smaller extent than in other countries. Farms measuring 30 ha or more steadily increased in number, whereas the number of farms measuring less than 30 ha decreased (FOAG 2019). Even if Swiss agriculture comprises comparatively small farms in an international context, the degree of mechanization is very high. Declining numbers of farms are contrasted by increasing registrations for agricultural machinery resulting in an average of 2.7 agricultural tractors per farm (FSO 2018a, b).

As only a small number of papers have dealt with adoption of PAT at the European level (Barnes et al. 2019), this paper contributes to extending this knowledge by investigating the technology adoption levels including PA enabling technologies of small-scale agriculture in Switzerland. In addition to recording country-specific adoption rates of individual technologies, the paper adds information to the published literature on drivers for PAT, allowing for a comparison with existing studies. To do this, a postal survey was conducted with farmers situated throughout Switzerland to generate knowledge about the status quo of mechanization and automation in different enterprises in Swiss agriculture. Thus, the two objectives of the present study were to find out (1) which kind of PAT have already been adopted by Swiss agriculture and (2) which characteristics of farm and farmers' are correlated with the adoption. The analyses were conducted by analyzing the survey data on the application of DAS and activities involving EMS such as nitrogen sensors. For both analyses, technologies relevant to Swiss agriculture were offered as possible answers. It should be noted that these answer options included also non-classical PA technologies. It was hypothesized that technology adoption does not occur to the same extent in different areas of agricultural production and that farm and farmers' characteristics, which, based on PA studies from other countries, are also important in the adoption process of agricultural technologies in Switzerland.

\section{Material and methods}

\section{Study sample and survey design}

This explorative work was part of a comprehensive study aiming at identifying the degree of mechanization and automation for economic labor considerations in different agricultural enterprises. In total, 17 questionnaires were developed, covering livestock farming and plant production. The distinction between the different enterprises was primarily defined on the basis of typical working procedures and the use of machinery in the respective enterprises (e.g. row crops, trees). Each agricultural enterprise belongs to one main farm type: plant production, livestock farming or combined farming. The number of questions, the length of the questionnaires and the specified answer possibilities differed depending on the agricultural enterprise. Farmers were reminded that the questions were only related to working steps on their own farms even if the machines were rented or belonged to a joint farming cooperation. Farm work done for others was not considered. Together with the Swiss Federal Statistical Office (FSO, Statistical Methods Section) 
a sampling plan was defined. Therefore, the Swiss Farm Structure Survey (FSS) from 2016 was used as the basis for determining the total population. The FSS is conducted annually to analyze information on structural, technical and socio-demographic factors and includes almost all Swiss farms (FSO 2016; Ferjani et al. 2015).

In the study, a two stage random sampling procedure of farms and enterprises was used. The first stage consisted of a Poisson sample of farms. The selection probabilities were constructed as follows: For each of the 17 considered enterprises of interest, a specific sampling design has been established along the lines of stratified simple random sampling. For each enterprise, the stratifications were based on an appropriate size variable, which was also used to calculate the sample sizes by means of optimal Neyman allocation. This step resulted for each farm in a set of 17 selection probabilities (in case a certain enterprise is not relevant for a farm, the corresponding selection probability can be interpreted as being zero). The first stage selection probability for each farm was calculated as the sum of the 17 enterprise-wise probabilities (with a cap at one). Due to the length of the questionnaires, it was decided that each farm may only receive a maximum of one questionnaire, even if the farm comprised several enterprises. This enterprise was chosen in a second sampling stage with probability proportional to size, where the enterprise specific sampling probabilities developed for the first sampling stage were used as size variable.

The detailed sampling procedure is shown in Table 5 in the Appendix. Since Switzerland is a multilingual country, questionnaires were sent in German, French or Italian.

In total, 4954 postal questionnaires, which covers almost $10 \%$ of all Swiss farms (51 620 farms in total in 2018) (FOAG 2018), were sent to farmers between January and March 2018. Finally, 2657 returned questionnaires could be analyzed further resulting in a response rate of $53.6 \%$.

As this study focused on PAT adoption in plant production, the questionnaires containing the following two questions were evaluated: 'Do you use any of the following Driver Assistance Systems (DAS)?' and 'In which of the following activities do you use Electronic Measuring Systems (EMS) (e.g. N-sensor, optical plant detection) on the machines?'. In both cases, the answer possibilities comprised technologies or activities relevant to Swiss agriculture, which in part differ from the international view of PA. The answer options for the use of DAS and EMS are explained in detail in Table 1.

In total, 827 questionnaires were used for further analysis including the following six enterprises: arable crops, fodder crops, vegetables, grapes, fruits and strawberries. The questions were used to classify farmers into PAT adopters and non-adopters. In both questions, multiple answers were possible.

\section{Farm and farmers' characteristics}

Based on previous research, the hypothesis was made that PAT adoption depends on farm and farmers' characteristics. Two continuous variables were considered including the age of the operation manager in years and number of livestock units. The investigated dichotomous variables were gender (female/male), the production system (conventional/organic) and the on farm working time (part-time/full-time).

Further, polytomous variables such as productivity zone, region, farm size and main farm type were investigated. The productivity zones are defined by the Swiss Federal Office for Agriculture (FOAG) as valley, hill and mountain zones. The classification depends, among other variables, on the climatic situation and vegetation period, the traffic conditions and topography including the proportion of slopes and steep slopes 
Table 1 Description of DAS and EMS answer options

Technology Description

\section{Driver assistance system}

Support system

Cruise control

Rear-view camera

Automatic data collection

Data transfer into field file

Headland management

Steering assistance system

Automatic steering systems

Row guidance

Parallel guidance

Recording of cutting edges

\section{Activities for electronic measuring systems}

Variable nutrient supply

Irrigation

Yield recording

Weed detection

Precision hoeing

Precision seeding

Moisture measurement of the harvest product
PA enabling technology and basis for consistent management by constant but different driving speeds

Camera based digital support tool, work simplification

Automatic data collection (position) is often used to transfer management tracks to other machinery, this makes only sense if the tracks are straight and have correct distances, which can be assured by driver assistant systems

The data transfer, being position or sensor information, to the field file is an eminent part of data collection and thus of PA. It is mentioned under DAS as part of its assistance properties

At the touch of a button, previously recorded functions are done automatically

Auto-steer without human input, most effective in combination with cruise control

Row guidance is an orientation along a crop row. Gives impulses to the steering unit and guides the machine automatically

A manual steering system by means of a light bar or LED display

Similar to row guidance but mainly used during the harvest and also for fodder crops; optical steering system guiding along the edges of the crop or tracks

Site-specific fertilisation

Site-specific irrigation

Automatic yield recording on the harvesting machine. Can include quality measures of the harvested product

Weeds and grass weeds are detected by sensors on the machine and can be distinguished from the crop plants, so that specific treatment can be applied

Intra-row mechanical weed removal using optical sensors to detect non-crop plants

Based on digital seeding maps, the sowing rate is determined by GPS positioning and is forwarded fully automatically to the control system of the machine

Quality indicator for cereals and forage crops. Can be also included in yield recording

(FOAG 1999). Because of unfavourable production conditions, it was hypothezied that farmers located in the mountain zone would be less likely to adopt PAT compared to farmers located in the valley.

For this study Switzerland was divided into seven major regions, namely the Lake Geneva region, Espace Mittelland, Northwestern Switzerland, Zurich, Eastern 
Switzerland, Central Switzerland and Tessin. The regional location of farms may be correlated to PAT adoption.

Farm size was classified depending on the size of the agricultural land into the following categories: 1 to less than 3 ha, 3 to less than 5 ha, 5 to less than 10 ha, 10 to less than 20 ha, 20 to less than 30 ha, 30 to less than 50 ha and 50 ha and more. Based on several studies, it was assumed that farm size is positively correlated with PAT adoption. Finally, the main farm types were investigated, with farm types being classified into specialist field crops, specialist horticulture, specialist permanent crops, specialist ruminant livestock, specialist granivore, mixed cropping, mixed livestock and mixed crops-livestock according to the data from the FSS.

\section{Data analyses}

\section{Average characteristics of adopters and non-adopters}

The results of the survey were analysed using the statistical software R Version 3.5. 3 (R Core Team 2013). In a first step, responders were divided into DAS and EMS adopters and non-adopters for each question separately; adopters were defined as those who selected at least one answer option to the relevant question (except 'none'), and nonadopters were defined as those that only choose 'none' or did not answer the question at all. In a second step, the frequencies for each DAS and EMS technology were evaluated.

For all further analyses, respondents were defined as PAT adopters, if they replied positively to at least one of the two questions (DAS and EMS). Non-adopters were defined by having chosen 'none' in both cases (see Table 6 in the Appendix for a detailed overview). Differences in average characteristics were tested using chi-squared tests for categorical variables and variance analysis and a Welch two-sample $t$-test for continuous scale data. Significant levels of differences between both groups were indicated as follows: $* p \leq 0.05, * * p \leq 0.01$ and $* * * p \leq 0.001$.

In Table 2, farm and farmers' characteristics for PAT adopters and non-adopters are shown by comparing their means. Significant differences in the average characteristics between the two subsamples are found for different topographic zones. Even if the majority of adopters and non-adopters are located in the valley, the proportion is significantly higher for adopters in this zone. On the contrary, the proportion of agricultural technology adopters located in the mountain zone is lower compared to the respective non-adopters. Further significant differences between the subgroups were found in the different classes of agricultural area. The proportion of farms with larger agricultural area ( $>50$ ha) was higher in the adopters' group. Conversely, the proportion of smaller farms (1-3 ha, $10 \leq 20$ ha) was higher for the non-adopters. However, regardless of adoption behavior, only a very small number of farmers had farms smaller than 5 ha. Furthermore, the number of livestock units was higher in the adopters' group, which underlines the results for farm size.

Among the PAT adopters, the proportion of arable crop and vegetable producing farms was significantly higher compared to the group of non-adopters. On the contrary, in the adopters' group, the proportion of fodder crops and grapes was significantly lower. Further significant differences between the averages in the subgroups were found for the main farm types where the mean was higher for adopters from specialist horticulture and lower for adopters from specialist permanent crop farming and specialist ruminant farming. 
Table 2 Distribution of average characteristics within the two subgroups of adopters and non-adopters

\begin{tabular}{|c|c|c|c|}
\hline & Adopter & Non-adopter & $\begin{array}{l}\text { Level of } \\
\text { signifi- } \\
\text { cance }\end{array}$ \\
\hline Number (n) & 346 & 481 & \\
\hline Age $($ Mean \pm SE $)$ & $48.9 \pm 0.04$ & $49.8 \pm 0.03$ & n.s. \\
\hline Gender $(0 / 1 ; 1=$ female $)$ & 0.02 & 0.05 & n.s. \\
\hline Production system $(0 / 1 ; 1=$ organic $)$ & 0.09 & 0.13 & n.s. \\
\hline Working time $(0 / 1 ; 1=$ full time $)$ & 0.97 & 0.95 & n.s. \\
\hline Livestock units $($ Mean \pm SE) & $28.9 \pm 0.13$ & $22.1 \pm 0.01$ & $* *$ \\
\hline \multicolumn{4}{|l|}{ Zone } \\
\hline Valley & 0.84 & 0.67 & $* * *$ \\
\hline Hill & 0.08 & 0.10 & n.s. \\
\hline Mountain zone & 0.08 & 0.24 & $* * *$ \\
\hline \multicolumn{4}{|l|}{ Agricultural area } \\
\hline $1 \leq 3$ ha & 0.00 & 0.02 & $*$ \\
\hline $3 \leq 5$ ha & 0.01 & 0.02 & n.s. \\
\hline $5 \leq 10$ ha & 0.04 & 0.06 & n.s. \\
\hline $10 \leq 20$ ha & 0.15 & 0.32 & $* * *$ \\
\hline $20 \leq 30$ ha & 0.20 & 0.28 & $* *$ \\
\hline $30 \leq 50$ ha & 0.25 & 0.20 & n.s. \\
\hline$\geq 50$ ha & 0.36 & 0.10 & $* * *$ \\
\hline \multicolumn{4}{|l|}{ Region } \\
\hline Lake Geneva region & 0.34 & 0.31 & n.s. \\
\hline Espace Mittelland & 0.23 & 0.23 & n.s. \\
\hline Northwestern Switzerland & 0.11 & 0.08 & n.s. \\
\hline Zurich & 0.08 & 0.06 & n.s. \\
\hline Eastern Switzerland & 0.16 & 0.20 & n.s. \\
\hline Central Switzerland & 0.06 & 0.11 & $* *$ \\
\hline Tessin & 0.01 & 0.03 & n.s. \\
\hline \multicolumn{4}{|l|}{ Agricultural enterprises } \\
\hline Arable crops & 0.24 & 0.14 & $* * *$ \\
\hline Fodder crops & 0.20 & 0.35 & $* * *$ \\
\hline Vegetables & 0.20 & 0.06 & $* * *$ \\
\hline Grapes & 0.14 & 0.25 & $* * *$ \\
\hline Fruits & 0.14 & 0.12 & n.s. \\
\hline Strawberries & 0.08 & 0.09 & n.s. \\
\hline \multicolumn{4}{|l|}{ Main farm types } \\
\hline Specialist field crops & 0.10 & 0.07 & n.s. \\
\hline Specialist horticulture & 0.16 & 0.04 & $* * *$ \\
\hline Specialist permanent crops & 0.25 & 0.32 & $*$ \\
\hline Specialist ruminant farming & 0.17 & 0.35 & $* * *$ \\
\hline Specialist granivore & 0.02 & 0.01 & n.s. \\
\hline Mixed cropping & 0.10 & 0.07 & n.s. \\
\hline Mixed livestock & 0.05 & 0.04 & n.s. \\
\hline Mixed crops-livestock & 0.15 & 0.11 & n.s. \\
\hline
\end{tabular}

*Indicates items that are significantly different from non-adopters $(* p \leq 0.05$, $* * p \leq 0.01$, *** $p \leq 0.001$, n.s. (not significant) $\mathrm{p}>0.05$ 


\section{Binary logistic regression}

To identify correlations between PAT adoption and farm and farmers' characteristics, a binary logistic regression was used. The binary decision to adopt the technology is denoted as $\mathrm{Y}$. $\mathrm{Y}$ is equal to 1 for adopters and 0 for non-adopters. The probability for adoption $\operatorname{Prob}(\mathrm{Y}=1)$ can be modelled in relation to a set of regressors $\mathrm{x}$ using the logit model:

$$
\operatorname{Prob}(Y=1 \mid x)=\frac{\exp \left(x^{\prime} \beta\right)}{1+\exp \left(x^{\prime} \beta\right)}=\Lambda\left(x^{\prime} \beta\right)
$$

$\Lambda\left(x^{\prime} \beta\right)$ is the cumulative logistic distribution function. Coefficient estimates $\beta$ are in contrast to the linear probability model not directly interpretable as marginal relations between the regressors and the probability of adoption. The marginal changes in the adoption probability related to changes in the regressors can be displayed as:

$$
\frac{\partial E[y \mid x]}{\partial x}=\Lambda\left(x^{\prime} \beta\right)\left[1-\Lambda\left(x^{\prime} \beta\right)\right] \beta
$$

The marginal changes alter with $\mathrm{x}$. Therefore, the marginal changes are shown, while keeping all other variables at their averages. These can be interpreted as changes in the probability to adopt in relation to a change in the regressor by one unit (Greene 2018).

Independent variables $\mathrm{x}$ included the previously described farm and farmers' characteristics. Different model specifications were tested with respect to the set of independent variables used to evaluate the robustness of the results (Table 7 in the Appendix). Error terms are clustered at the enterprise level as the error term are expected to be correlated within each enterprise.

\section{Results}

\section{Relative frequency of technologies used}

Figure 1 shows the percentage of adopters and non-adopters in the different agricultural enterprises for DAS and EMS separately as well as for PAT adoption (users of at least one queried technology). On average, across all enterprises, $37 \%$ of the surveyed farmers already used at least one function of DAS, whereas only $17 \%$ of farmers were EMS adopters (Table 6 in Appendix). However, vegetable production constituted the only enterprise having more DAS adopters than non-adopters with an adoption rate of $67 \%$. About $44 \%$ of arable crop- and fruit farmers adopted any kind of DAS followed by strawberry farmers (36\%). For grapes and fodder crops, the adoption was lowest at $26 \%$ and $25 \%$, respectively. EMS were used less with higher non-adopter rates compared to adopters within all agricultural enterprises. Again, arable crops and vegetables had the highest adoption rate at $34 \%$ and $31 \%$, respectively. The EMS adoption for the other enterprises was between 10 and $13 \%$. Only about $30 \%$ of DAS adopters were also EMS adopters in this study, resulting in even higher adoption rates for the group of PAT except in strawberry production.

The two questions analyzed related to PAT adoption as well as the frequencies of application in the different agricultural enterprises are shown in Table 3. The table lists the percentages of farmers using DAS, followed by the percentages of activities in which EMS are 


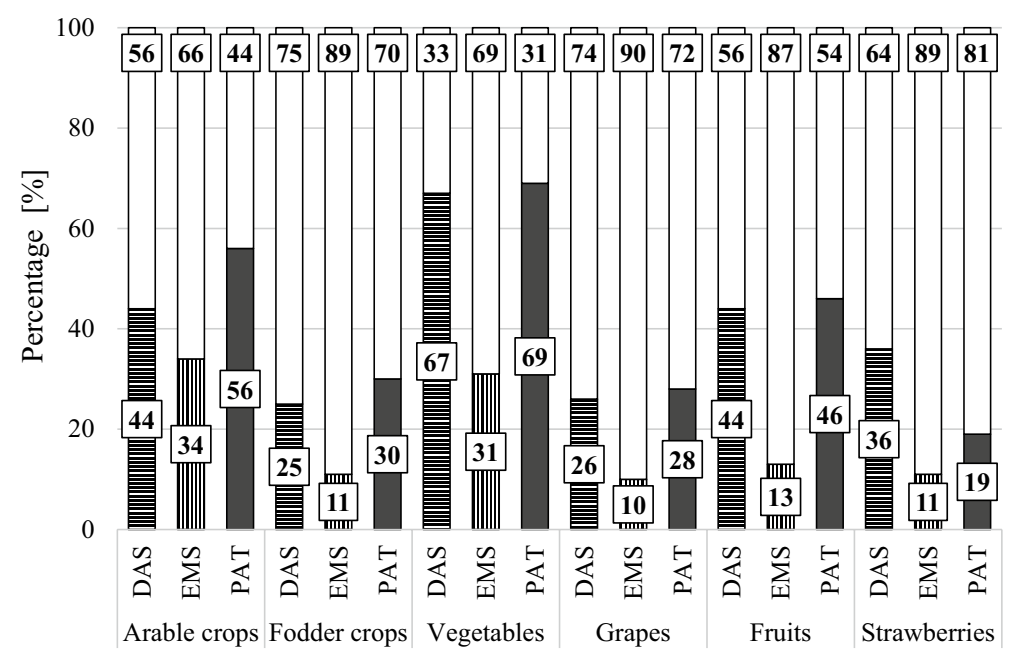

$\square$ Adopter $\square$ Non-adopter

Fig. 1 Percentage of adopters and non-adopters for DAS, EMS and PAT (adoption of at least one DAS or EMS technology) for different agricultural enterprises

used. Most of the farmers indicated using none of the specified technologies. However, the number differed depending on the type of technology with $63 \%$ and $83 \%$, respectively, for Questions 1 and 2.

For all agricultural enterprises, cruise control was the most frequent application of a DAS except for arable crops, where the proportion was almost similar for the application of rear-view cameras. In vegetable production, about $45 \%$ of surveyed farmers indicated the use of rear-view cameras, and the frequency of the application of automatic steering systems was high at $32 \%$. About $11 \%$ of arable crop farmers indicated using DAS in headland management and as parallel driving aids. In vegetable production, $26 \%$ and $28 \%$ of respondents used these DAS applications, respectively. Other answer options were selected by less than $20 \%$ of respondents for all agricultural enterprises as shown in Table 3.

Moisture measurement of harvest product was the most frequent EMS application in arable crops with a positive response rate of about $20 \%$. In vegetable production, about $11 \%$ of farmers reported the application of EMS in hoeing. For all other agricultural enterprises and answer options, the application of EMS was below 10\% (lower part of Table 3).

\section{Binary logistic regression analysis}

A binary logistic regression was used to identify correlations between PAT adoption and farm and farmers' characteristics. The estimated marginal changes indicate the magnitude of the correlation, or the change in the adoption probability when changing the respective independent variable by one unit. To evaluate the robustness of the results, different model specifications were tested with respect to the set of independent variables used (Table 7 in the Appendix), where Model 1 constitutes the full set of variables. The significant results are shown in Table 4. Neither livestock units, age, gender, production system nor working time were found to be significantly correlated to PAT adoption. Regarding the zones, 
Table 3 Frequencies (\%) for the use of DAS and EMS for the different agricultural enterprises

\begin{tabular}{|c|c|c|c|c|c|c|c|}
\hline Enterprise & Arable crops & Fodder crops & Vegetables & Grapes & Fruits & Strawberries & $\Sigma$ \\
\hline Number of responses & $\mathrm{n}=148$ & $\mathrm{n}=235$ & $\mathrm{n}=97$ & $\mathrm{n}=166$ & $\mathrm{n}=105$ & $\mathrm{n}=69$ & $\mathrm{n}=820$ \\
\hline None & 56 & 75 & 33 & 74 & 56 & 64 & 63 \\
\hline Cruise control & 23 & 14 & 45 & 22 & 27 & 19 & 23 \\
\hline $\begin{array}{l}\text { Automatic steering } \\
\text { systems }\end{array}$ & 16 & 1 & 33 & 3 & 16 & 7 & 10 \\
\hline Rear-view camera & 24 & 8 & 32 & 5 & 4 & 9 & 13 \\
\hline $\begin{array}{l}\text { Automatic data col- } \\
\text { lection }\end{array}$ & 3 & 2 & 6 & 3 & 2 & 3 & 3 \\
\hline $\begin{array}{l}\text { Data transfer to field } \\
\text { file }\end{array}$ & 1 & 2 & 12 & 1 & 3 & 1 & 3 \\
\hline Row guidance & 6 & na & 18 & 1 & 8 & 6 & 7 \\
\hline $\begin{array}{l}\text { Headland manage- } \\
\text { ment }\end{array}$ & 11 & 6 & 26 & na & na & 6 & 11 \\
\hline Parallel guidance & 11 & 6 & 28 & na & na & 9 & 11 \\
\hline $\begin{array}{l}\text { Recording of cutting } \\
\text { edges }\end{array}$ & 2 & 1 & 1 & na & na & na & 1 \\
\hline Others & 1 & 1 & 4 & 2 & 3 & 1 & 2 \\
\hline
\end{tabular}

2. In which of the following activities do you use electronic measuring systems (e.g. Nitrogen sensor, optical plant detection) on the machines?

\begin{tabular}{|c|c|c|c|c|c|c|c|}
\hline Enterprise & Arable crops & Fodder crops & Vegetables & Grapes & Fruits & Strawberries & $\sum$ \\
\hline Number of responses & $\mathrm{n}=140$ & $\mathrm{n}=231$ & $\mathrm{n}=93$ & $\mathrm{n}=165$ & $\mathrm{n}=102$ & $\mathrm{n}=65$ & $\mathrm{n}=820$ \\
\hline None & 66 & 89 & 69 & 90 & 87 & 89 & 83 \\
\hline Nutrient supply & 9 & 4 & 9 & 3 & 4 & 9 & 6 \\
\hline Irrigation & 1 & 0 & 9 & 1 & 8 & 9 & 3 \\
\hline Yield recording & 5 & 2 & 2 & 1 & 1 & 2 & 2 \\
\hline Weed detection & 0 & 0 & 6 & na & na & 0 & 1 \\
\hline Precision hoeing & 1 & na & 12 & na & na & 0 & 4 \\
\hline $\begin{array}{l}\text { Moisture measurement } \\
\text { of harvest product }\end{array}$ & 20 & 6 & na & na & na & na & 12 \\
\hline Others & 1 & 2 & 2 & 5 & 3 & 2 & 3 \\
\hline
\end{tabular}

na indicates that the answer option was not available in the respective agricultural enterprise

farms located in the mountain zone were found to be less likely to adopt compared to the baseline category valley. Moreover, farms with an agricultural area of 1 ha to less than 3 ha were $36 \%$ points less likely to adopt technology compared to the base category of farms of 10 ha to $20 \mathrm{ha}$, which constitutes the medium category and represents the average farm size in Switzerland. On the contrary, large Swiss farms (i.e. farms with more than 30 ha) were more likely to adopt PAT. Further, grape farmers were less likely to adopt compared to the base category of arable crop farms. A weak negative correlation could also be found for fruit production and PAT adoption. In addition, a weak correlation with the main farm type specialist permanent crops, which also includes viticulture, and adoption was observed. 
Table 4 Significant results of binary logistic regression of characteristics correlated with PAT adoption

\begin{tabular}{|c|c|c|c|}
\hline & Marginal effects & SE & z-values \\
\hline \multicolumn{4}{|l|}{ Zone (base category: valley) } \\
\hline Mountain zone & -0.15 & 0.04 & $-4.17 * * *$ \\
\hline \multicolumn{4}{|c|}{ Agricultural area (base category: 10 to 20 ha) } \\
\hline $1 \leq 3$ ha & -0.36 & 0.00 & $-115.69 * * *$ \\
\hline $30 \leq 50$ ha & 0.20 & 0.06 & $3.06 * *$ \\
\hline$\geq 50$ ha & 0.48 & 0.07 & $7.32 * * *$ \\
\hline \multicolumn{4}{|c|}{ Agricultural enterprises (base category: arable crops) } \\
\hline Grapes & -0.25 & 0.02 & $-9.99 * * *$ \\
\hline Fruits & -0.08 & 0.04 & $-1.97 *$ \\
\hline \multicolumn{4}{|c|}{ Main farm type (base category: specialist field crops) } \\
\hline Specialist permanent crops & 0.26 & 0.10 & $2.54 * *$ \\
\hline
\end{tabular}

Number of observations $=608$; Log-likelihood: -341.26 ; Deviance: 682.52 ; AIC: 746.52; BIC: 887.65

$* \mathrm{p} \leq 0.05$

$* * \mathrm{p} \leq 0.01$

$* * * \mathrm{p} \leq 0.001$

To examine correlations between farm and farmers' characteristics for the different types of technologies, PAT adoption (Model 1) was compared to DAS and EMS adoption (Models 7 and 8) (Table 8 in the Appendix). An additional strong positive correlation was found for the enterprise strawberries with EMS adoption. However, the results were robust across the adoption of PAT, DAS and EMS for the effects of zone, farm size and for the enterprise grapes.

\section{Discussion}

The results of this study extend the current research on the adoption of agricultural technologies and differs in particular in the consideration of Switzerland as an example of a country with small-scale, but highly mechanized agriculture. The study investigated the adoption of two superordinate types of agricultural technologies enabling PA for different agricultural enterprises. The sample selection procedure considered almost all Swiss farms as a basis for random sampling and more than 800 responders, corresponding to more than $5 \%$ of all Swiss farms, replied regarding the use of DAS and EMS. This makes the study valuable and much more representative compared to the database of many other published studies. In comparison, Tamirat et al. (2018) evaluated 260 questionnaires, mainly from Denmark with regard to PA adoption; Winstead et al. (2010) based their findings on the use of PA technologies in the U.S. on 42 questionnaires. Reichardt and Jürgens (2009) interviewed between 400 and 2300 farmers in Germany (a market ten times larger than Switzerland with a number of farms about six times larger than in Switzerland) in several years; but with the bias that they did this at famous agricultural fairs, where more technically inclined farmers are likely to be found. Thus, these results have to be interpreted with care.

A country-specific comparison of technology adoption rates is also difficult, because of the different technologies surveyed. In the study of Tamirat et al. (2018) based on less representative data from Denmark and Germany, an adoption rate of $19 \%$ was shown. 
However, the authors focused only on GPS-assisted PA and/or auto-guidance, which may be comparable to DAS in the present study. Similar results were obtained by Reichardt and Jürgens (2009) who reported that most of the surveyed German farmers (at specific agricultural fairs) did not use any PF technology but without further specification. However, the study was done almost ten years ago. In a recent study by Paustian and Theuvsen (2017), an adoption rate of 30\% of PF technology was found in Germany based on 227 online questionnaires. However, the authors did not use random sampling nor specify the PF technologies, making a comparison between the studies difficult.

In this study, DAS technologies comprised several technologies, which support or assist the driver in their farming activities and which are not typically included in other PA adoption studies. However, the presented technologies are named more specific than in most other studies, which either not include such assistance technology or summarize individual technologies under one technology, often called 'machine guidance'. Therefore, the results show a classification of individual technologies into technology groups and results differentiated adoption rates, which allows a transparent evaluation and comparison between studies. A uniform definition of PA, as issued by ISPA (ISPA 2019), in combination with an overview of included technologies would bring more clarity in this context.

Reasons for low PAT adoption rates in European countries could be small farm size together with high acquisition costs (Reichardt and Jürgens 2009). Even though the current survey did not ask for motivations of PAT adoption, this result could also be important in Switzerland, as farms, particularly small farms, have to cope with large acquisition costs relative to overall profit. In this study, PAT adoption was positively correlated with a large farm size by area and vice versa, whereby the definition of a large farm size varies by study. While in the recent study the largest farm category covered 50 ha and more, which is more than twice the Swiss average, German farmers with large farm sizes of more than 250 ha were found to be more likely to invest in technologies enabling PA (Reichardt and Jürgens 2009). In addition, in a review by Pierpaoli et al. (2013) farms with 500 ha and more were defined as large (Pierpaoli et al. 2013). In this context, the results of the current study confirm that adoption happens in the upper part of the farm size distribution. However, farm size is relative, so country-specific studies are important as adoption rates based on foreign studies can lead to incorrect conclusions.

Whether age is an important factor in the adoption process is not clear from the literature since the results from other studies are inconsistent regarding the operators' ages (Tey and Brindal 2012). In this study, age was not correlated with PAT adoption.

In terms of agricultural enterprises, $67 \%$ of the surveyed vegetable farmers had already adopted DAS technology in the current study. With 1.1 billion Swiss Francs (CHF; conversion rate to US $\$$ is roughly $1: 1$ ) vegetable farming generates about $14 \%$ of the total production value of Swiss agriculture but covers only about $1 \%$ of the agricultural area in the country (ASVP and AIS 2014; FSO 2017). In contrast to this, fodder crops make up two thirds of the total agricultural area (ASVP and AIS 2014) but the production value of fodder crops (e.g. grassland/pasture) is similar at 1 billion CHF or almost $10 \%$ of the total production value of Swiss agriculture (FSO 2017). However, fodder crop production showed the lowest DAS adoption. High adoption rates in vegetable production might be due to several reasons. Obviously, high production values favor the adoption of or investment in new technologies. The advantages of adopting DAS or EMS are more significant for crops with high returns, particularly for field vegetable crops for which fields are smaller and crops are often produced in a series of different ages next to each other. In this case, DAS and EMS are more often used compared to, for example, arable crops or fodder crops for which the whole field is cultivated homogeneously. Additionally, in high-value crops, 
losses from small driving errors or mismanagement also reflect higher financial losses linking to an immediate gain. Furthermore, vegetable farmers might be more experienced in the automatic control management of humidity, fertilization and temperature if they also have intensive greenhouse production (Roldán et al. 2017), where this is essential for producing high-quality products. Therefore, vegetable farmers are likely more affine with control technology.

Moreover, fodder crops are typically grown in the mountain zone, where there are hardly any production alternatives because other crop specializations are not feasible. Therefore, farm location can be considered an important factor for the PAT adoption in fodder crops. This fact is clearly supported by the results of the binary regression showing that farmers from the mountain zone are less likely to adopt compared to farmers located in the valley areas.

Across all models of the binary regression, grape production was less likely to see the adoption of PAT, regardless of the type of technology. An explanation could be the cultivation on steep slopes, where the possibilities for mechanization and, therefore, PAT are currently still limited. The application of Unmanned Aerial Vehicles (UAVs) such as drones could be useful to promote agricultural management in these difficult areas (Matese et al. 2015). In this context, Switzerland is the first European country that has developed a licensing procedure that could trigger the increased use of drones for pesticide applications in the future (FOCA 2019; Agroscope 2019).

The adoption of DAS was higher than for EMS possibly because some DAS technologies are not classical PA technologies but more transition technologies, which are easier to apply. Thus the level of usage difficulty might be decisive. These results confirm previous studies done e.g. by Schimmelpfennig (2016) and Miller et al. (2019) in the U.S., showing that DAS-type technologies are more readily adopted than EMS-type technologies. However, this observation could be confirmed in Switzerland, a country with different farm structure and lower average farm size. DAS technologies are well-established and are often part of the basic equipment of new machines. Thus, they are easy for farmers to learn and use. The application of EMS is often more complex since they are seldom integrated into machinery, making data exchanges between the machines and devices necessary. Although data transfer standards have been developed and are largely used, the difficult connectivity between devices and machines of different manufacturers is still often a practical hurdle for adoption from a technical point of view. Thus, a better differentiation of EMS technologies and their uses could benefit a better target-oriented implementation. Variation in the adoption rates related to different technologies was also shown for the adoption of GPSbased applications (e.g. area measurement or soil mapping) with VRNT (e.g. site-specific fertilization), which is often lower for the latter (Reichardt and Jürgens 2009). While the first relies on the machine terminal or requires interfacing of only one sensor, variable rate application needs the combination of a sensor for the machine terminal and an application device, making the connection much more complex.

According to Winstead et al. (2010), yield monitoring was the most frequently used information-intensive technology (about $40 \%$ of farmers used it) among U.S. farmers from Alabama and Florida in almost equal proportions with or without GPS use. Furthermore, it could be shown that the adoption of yield monitors was more likely for large farms (Winstead et al. 2010). However, the authors used non-representative data from audience responses at a conference. Still, in comparison only $2 \%$ of Swiss farmers used EMS 
for yield recording, which could again be related to small farm sizes in an international context.

The integration of remote sensing technologies or mapping services, which currently develop very quickly, allows also for variable rate or precision management without tractor-based sensors. This approach relies on the upload of map information on the machine terminal such as satellite derived maps, harvest or yield maps or soil zones, eventually making the use of some technologies easier and cheaper (Matese et al. 2015; Mulla 2013).

The application of automatic data collection or data transfer to field file is still low, which could show that technologies are partially used to reduce physical workloads but not yet to evaluate the performance of crop and crop management to support decision-making. However, automatic collection and forwarding of data is a fundamental step towards smart farming, and only if data processing and analysis is applied, the full potential can be realised in the future. To promote the digital transformation in Swiss agriculture, the Federal Council decided in 2016 to make an active contribution to the digitalisation of the Swiss agricultural and food sectors (FOAG 2016). However, when promoting PAT, it is important to consider the type of agricultural enterprise and the location, otherwise high adopters could be preferred (e.g. valley zone and vegetable production), which could result in undesirable side effects on the structure of Swiss agriculture. On the other hand, it could also be actively used to promote certain agricultural enterprises, for example with regard to their environmental impact (e.g. nitrate leaching per ha).

Even if adoption of PA enabling technologies is still low in some individual agricultural enterprises, the introduction of digital or shared technologies could contribute to higher adoption rates. For example, the application of drones could be useful in order to promote the management in difficult terrains (e.g. the mountain zone) but also to simplify the monitoring of crops, identify pests, estimate constituents or facilitate precision spraying application such as for pesticides or nutrients (King 2017; Giles 2016; Xiongkui et al. 2017; SATW 2019). This aspect is particularly important in grapes, where the use of UAVs will support the agricultural management of slopes in the future (Santesteban et al. 2017; Matese et al. 2015). Currently, there are three companies that already offer UAV pesticide application in grapes in Switzerland (Finger et al. 2019). The usage of technologies to target pesticide applications to reduce the large numbers of pesticide treatments (e.g. in horticultural crops) contributes to the environmentally friendly and cost-saving handling of resources. However, the cost-saving aspect of PAT adoption during, for example, pesticide applications is not enough because acquisition costs are often high and advantages need to be extended to make the application more attractive for lower-value crops and small-scale farmers (Finger et al. 2019).

Another approach to promote the implementation can be seen in the example of France. French farmers are obliged to report $\mathrm{N}$ fertilization efficiency measures and VRA maps or a satellite-based service are accepted proof. The decision-support tool 'FARMSTAR', which provides variable rate application maps to farmers in order to support the right amounts of field-inputs, was used already by French 18000 farmers in 2016 (Soenen et al. 2017; Coquil et al. 2005). However, linking, for example, direct payments to N-monitoring of the fertilization of grassland and arable land in Switzerland would also create the possibility that more PA enabling technologies could be used for crops that generate little added value per se.

Shepherd et al. (2018) summarized that the use of technologies must also support farmers to meet the growing demands of consumers and regulators (Shepherd et al. 2018). 
Thus, technology adoption is not limited to farms but could be extended to the entire value chain including the post-harvest processing, storage and retail. Besides the above results, some limitations in this study leave space for further research on agricultural technology adoption enabling the implementation of PA in Swiss agriculture. The survey focused on the adoption of DAS and EMS with regard to the main agricultural enterprises and the most common working steps regarding each enterprise. Thus, not all possible technologies could be listed and there are possibly other technologies already used by Swiss farmers (e.g. Smartphone Apps, drones) that are not covered in this study. Furthermore, it is also possible that farmers are not entirely sure which technologies are actually used on their fields if they are carried out by contractors or in farming co-operations. In addition, there is no gradation between the different technologies queried. A division into old technologies that have long been available on the market and new technologies could be helpful in the future. The intensity of use also remains unclear; for example, it is not measured as a percentage of land area. Furthermore, there is a lack of farmers' personal assessment as to why they do not use available technologies. Thus, questions to be answered in the future are as follows: Are small farms really lagging behind or just not adopting because it provides no added value? Are other, cheaper technologies more interesting for small farms? How could the use of PA enabling technologies be promoted in order to exploit its benefits and potential? Determinants to drive development forward with a special focus on small structured farms should also be analysed as well as a more detailed consideration of the intensity of technology use.

\section{Conclusion}

This representative study found that the PAT adoption rate of individual agricultural enterprises was very heterogeneous in Switzerland. In general, vegetable and arable crop producers were strong adopters, but the adoption was low for fodder crops and grapes. Adoption trends in Switzerland are in line with results from abroad, showing that DAS-type technologies are more frequently used in practice than EMS-type technologies. This result indicates that technologies are used rather to reduce physical workloads than to support crop or management decisions. The effects of farm size as well as for the enterprise grapes were robust across the adoption of DAS, EMS and PAT.

For future research, these results can be used as a basis to develop a more-detailed survey that includes farmers' expectations of PA. Thus, working areas could be identified where new technologies would bring an added value aiming to managing small farms more efficiently, more economically, less labor-intensively and in a more economically friendly way. Also, the connection between agricultural policy goals such as nature conservation policies or direct payments and PAT adoption could be another important research question directed at understanding the drivers and barriers in the adoption process in the agricultural sector.

Acknowledgements The authors appreciate the support and cooperation of J. Potterat and A. Zesiger from the Swiss Federal Statistical Office in developing a sampling scheme and for carrying out the drawing of the sample. Further, thanks are due to the Swiss Federal Office for Agriculture for supporting the project 'Adoption and diffusion of new technologies in agriculture - status, determinants and future prospects'. Moreover, we would like to convey special thanks to Ruedi Stark, who was involved in the design and realisation of the questionnaires. The authors are grateful to Joanna Stachowicz, Janika Lutz and Leonie Hart for the data capture, editing and digitalisation of the questionnaires and Abu Zar Md. Shafiullah for statistical support. 


\section{Compliance with ethical standards}

Conflict of interest The authors declare that they have no conflict of interest.

Open Access This article is licensed under a Creative Commons Attribution 4.0 International License, which permits use, sharing, adaptation, distribution and reproduction in any medium or format, as long as you give appropriate credit to the original author(s) and the source, provide a link to the Creative Commons licence, and indicate if changes were made. The images or other third party material in this article are included in the article's Creative Commons licence, unless indicated otherwise in a credit line to the material. If material is not included in the article's Creative Commons licence and your intended use is not permitted by statutory regulation or exceeds the permitted use, you will need to obtain permission directly from the copyright holder. To view a copy of this licence, visit http://creativecommons.org/licenses/by/4.0/.

\section{Appendix}

See Tables 5, 6, 7, and 8 .

Table 5 Sampling plan on the basis of the Swiss Farm Structure Survey (FSS) of 2016

\begin{tabular}{|c|c|c|c|c|c|c|c|}
\hline \multirow[t]{2}{*}{ Enterprises } & \multirow{2}{*}{$\begin{array}{l}\text { Limit value for } \\
\text { exclusion of } \\
\text { small farms }^{\mathrm{a}}\end{array}$} & \multicolumn{5}{|c|}{ Stratification } & \multirow{2}{*}{$\begin{array}{l}\text { Number of } \\
\text { questionnaires } \\
\text { sent }\end{array}$} \\
\hline & & 1 & 2 & 3 & 4 & 5 & \\
\hline Arable crops & 10 ha & $10.01-20$ & $20.01-30$ & $30.01-50$ & $>50$ & & 222 \\
\hline Fodder crops & 10 ha & $10.01-20$ & $20.01-30$ & $30.01-50$ & $>50$ & & 518 \\
\hline Vegetables & $3 \mathrm{ha}$ & $3.01-10$ & $10.01-20$ & $>20$ & & & 175 \\
\hline Grapes & 0.2 ha & $0.21-1$ & $1.01-2$ & $2.01-5$ & $5.01-10$ & $>10$ & 319 \\
\hline Tall fruit trees & 20 & $21-50$ & $51-150$ & $>150$ & & & 421 \\
\hline Fruits & $1 \mathrm{ha}$ & $1.01-3$ & $3.01-10$ & $10.01-20$ & $>20$ & & 182 \\
\hline Bush berries & 0.1 ha & $0.11-0.3$ & $0.31-1$ & $1.01-2$ & $>2$ & & 109 \\
\hline Strawberries & 0.1 ha & $0.11-0.3$ & $0.31-1$ & $1.01-2$ & $>2$ & & 122 \\
\hline Dairy cattles & 10 & $11-25$ & $26-50$ & $51-100$ & $>100$ & & 450 \\
\hline Suckler cows & 5 & $6-10$ & $11-25$ & $26-50$ & $>50$ & & 200 \\
\hline Beef cattles & 5 & $6-10$ & $11-25$ & $26-50$ & $51-100$ & $>100$ & 513 \\
\hline Breeding pigs & 10 & $11-20$ & $21-50$ & $50-100$ & $>100$ & & 312 \\
\hline Porkers & 10 & $11-50$ & $51-200$ & $201-500$ & $501-1000$ & $>1000$ & 255 \\
\hline Meat sheeps & 25 & $26-50$ & $51-150$ & $>150$ & & & 244 \\
\hline Dairy goats & 5 & $6-25$ & $26-50$ & $>50$ & & & 279 \\
\hline Laying hens & 50 & $51-100$ & $101-500$ & $501-2000$ & $2001-5000$ & $>5000$ & 265 \\
\hline Broilers & 1000 & $1001-5000$ & $>5000$ & & & & 368 \\
\hline
\end{tabular}

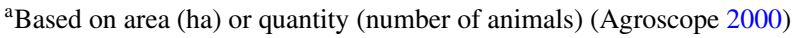




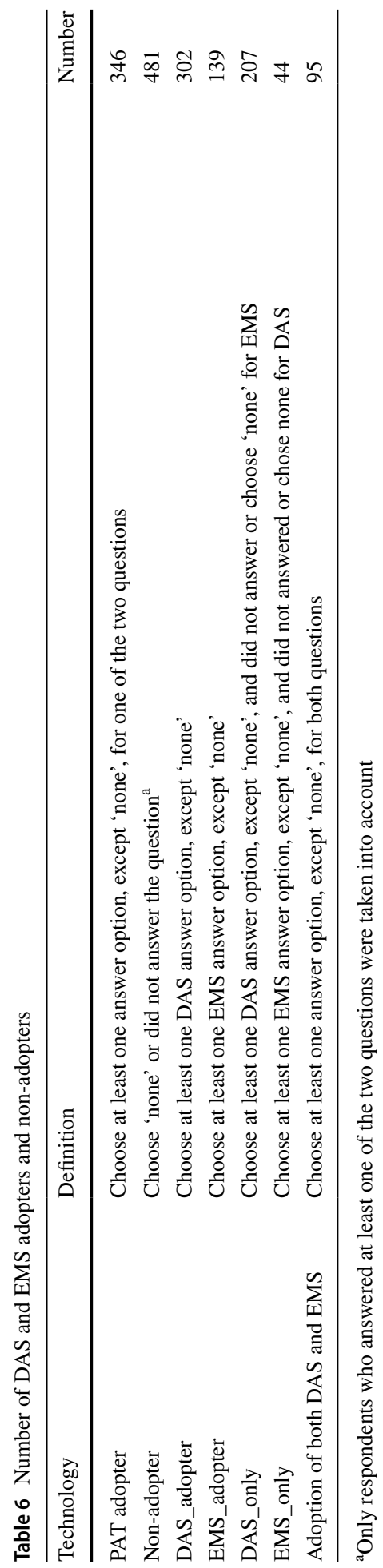




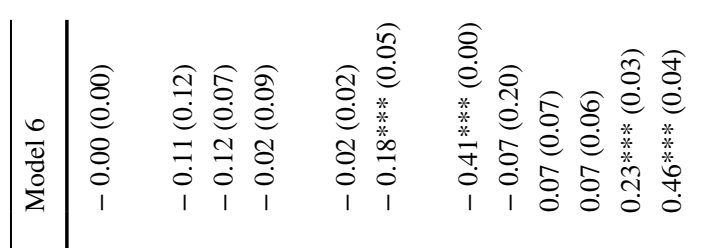

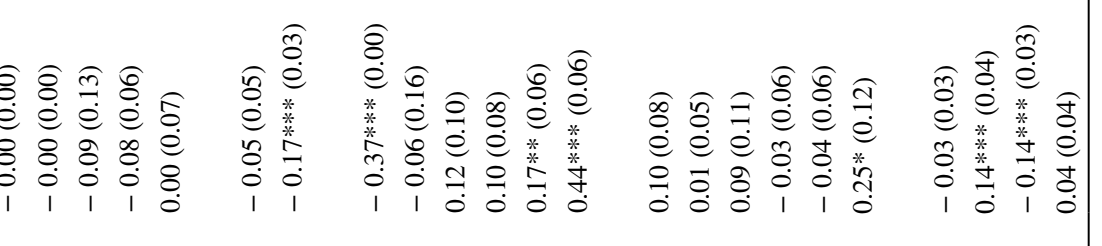

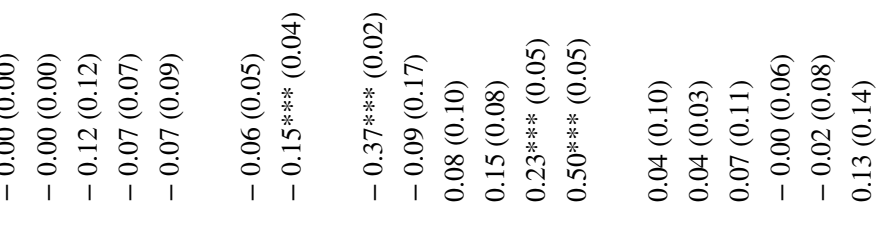

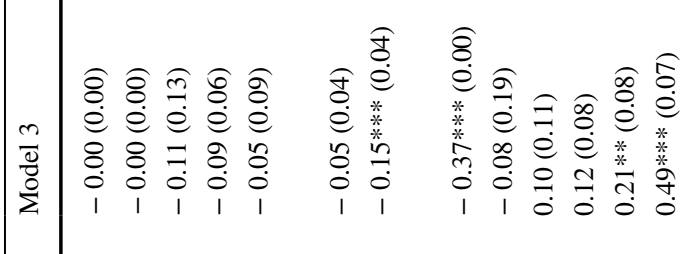

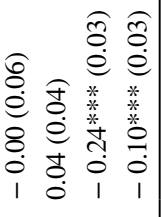

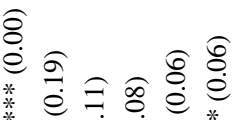

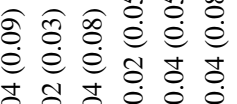

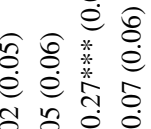

$\begin{array}{cccc}0 & 0 & 0 & 0 \\ 0 & 0 & 0 & 0 \\ 0 & 0 & 1 & 1\end{array}$

$\frac{n}{\frac{\pi}{0}}$

范

$$
\text { (2) }
$$

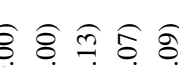

ר

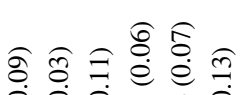

กิ

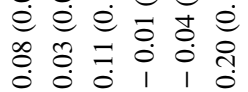

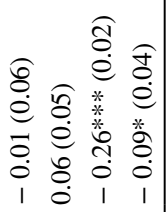

$\begin{array}{llllll}2 & 0 & 0 & 0 & 0 & 0 \\ 0 & 0 & 0 & 0 & 0 \\ 1 & 1 & 1 & 1 & 1\end{array}$

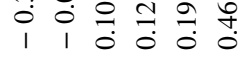

$\begin{array}{lllll}0 & 0 & 1 & 1 & 0\end{array}$

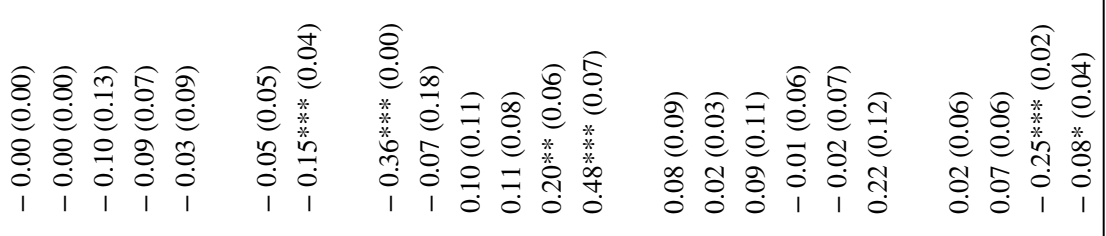

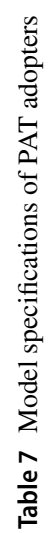

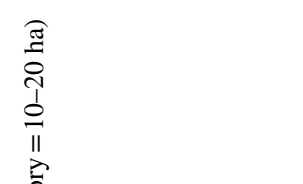

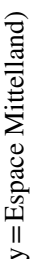

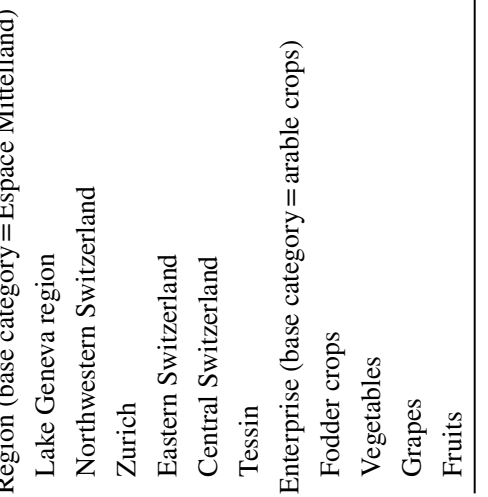




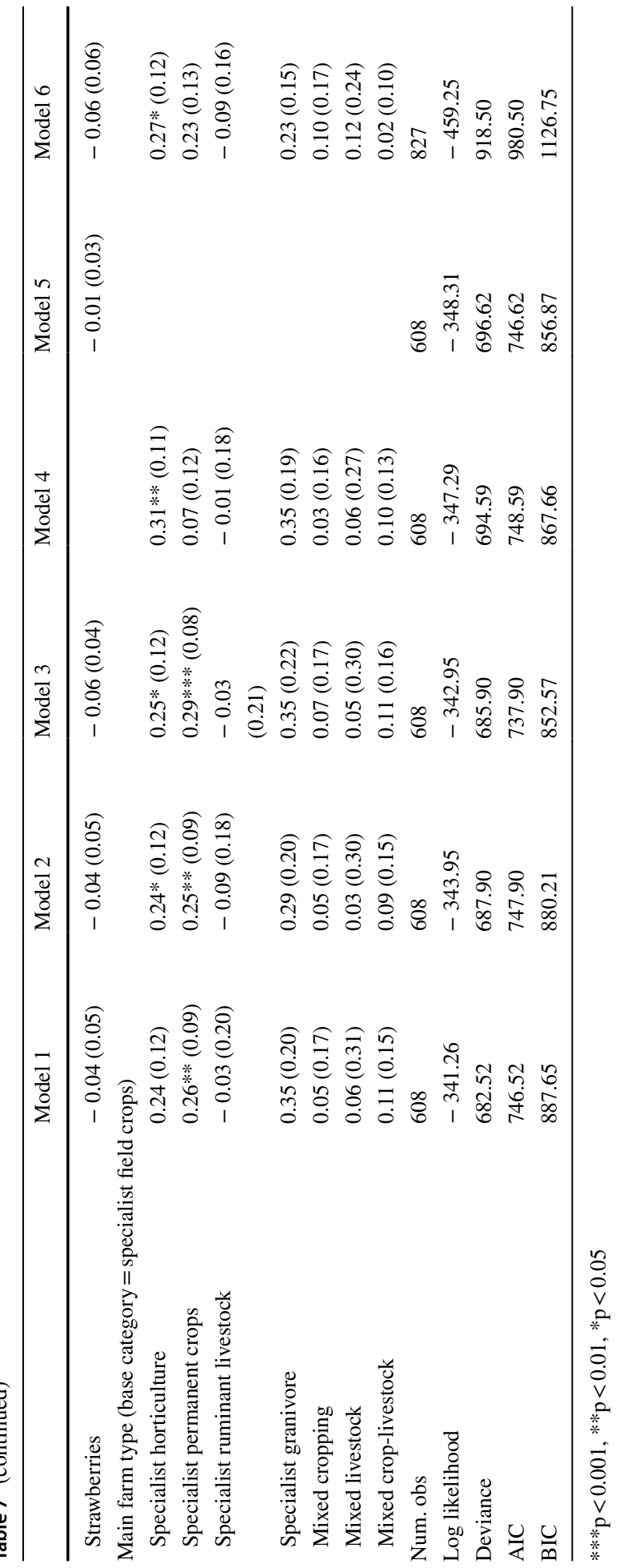


Table 8 Model comparison of PAT adopters, DAS adopters and EMS adopters

\begin{tabular}{|c|c|c|c|}
\hline & $\begin{array}{l}\text { Model } 1 \\
\text { PAT }\end{array}$ & $\begin{array}{l}\text { Model } 7 \\
\text { DAS }\end{array}$ & $\begin{array}{l}\text { Model } 8 \\
\text { EMS }\end{array}$ \\
\hline Livestock units & $-0.00(0.00)$ & $0.00(0.00)$ & $0.00(0.00)$ \\
\hline Age (years) & $-0.00(0.00)$ & $-0.00(0.00)$ & $0.00(0.00)$ \\
\hline Gender $(1=$ female $)$ & $-0.10(0.13)$ & $-0.10(0.10)$ & $-0.02(0.06)$ \\
\hline Production system $(1=$ organic $)$ & $-0.09(0.07)$ & $-0.06(0.06)$ & $-0.01(0.02)$ \\
\hline Working time ( $1=$ full-time $)$ & $-0.03(0.09)$ & $-0.01(0.12)$ & $-0.06(0.13)$ \\
\hline \multicolumn{4}{|l|}{ Zone $($ base category $=$ valley $)$} \\
\hline Hill & $-0.05(0.05)$ & $-0.05(0.06)$ & $-0.01(0.02)$ \\
\hline Mountain zone & $-0.15 * * *(0.04)$ & $-0.11 * *(0.04)$ & $-0.04 *(0.02)$ \\
\hline \multicolumn{4}{|c|}{ Agricultural area (base category $=10-20 \mathrm{ha}$ ) } \\
\hline $1 \leq 3$ ha & $-0.36 * * *(0.00)$ & $-0.31 * * *(0.00)$ & $-0.10 * * *(0.01)$ \\
\hline $3 \leq 5$ ha & $-0.07(0.18)$ & $-0.16(0.16)$ & $0.02(0.07)$ \\
\hline $5 \leq 10$ ha & $0.10(0.11)$ & $0.04(0.07)$ & $0.13 * *(0.04)$ \\
\hline $20 \leq 30$ ha & $0.11(0.08)$ & $0.11(0.08)$ & $0.06(0.03)$ \\
\hline $30 \leq 50$ ha & $0.20 * *(0.06)$ & $0.20 * *(0.07)$ & $0.07 *(0.03)$ \\
\hline$\geq 50$ ha & $0.48^{* * *}(0.07)$ & $0.45^{* * *}(0.06)$ & $0.24 * * *(0.03)$ \\
\hline \multicolumn{4}{|c|}{ Region (base category $=$ Espace Mittelland) } \\
\hline Lake Geneva region & $0.08(0.09)$ & $-0.02(0.08)$ & $0.10 * *(0.04)$ \\
\hline Northwestern Switzerland & $0.02(0.03)$ & $0.05(0.06)$ & $0.00(0.02)$ \\
\hline Zurich & $0.09(0.11)$ & $0.04(0.09)$ & $0.03(0.07)$ \\
\hline Eastern Switzerland & $-0.01(0.06)$ & $-0.02(0.03)$ & $-0.01(0.04)$ \\
\hline Central Switzerland & $-0.02(0.07)$ & $0.03(0.09)$ & $-0.01(0.06)$ \\
\hline Tessin & $0.22(0.12)$ & $0.18 *(0.07)$ & $-0.09 * * *(0.00)$ \\
\hline \multicolumn{4}{|c|}{ Type of farming (base category $=$ arable crops) } \\
\hline Fodder crops & $0.02(0.06)$ & $0.03(0.05)$ & $-0.01(0.03)$ \\
\hline Vegetables & $0.07(0.06)$ & $0.10(0.06)$ & $0.01(0.03)$ \\
\hline Grapes & $-0.25 * * *(0.02)$ & $-0.12 * *(0.05)$ & $-0.06 * *(0.02)$ \\
\hline Fruits & $-0.08 *(0.04)$ & $0.02(0.06)$ & $-0.06 * *(0.02)$ \\
\hline Strawberries & $-0.04(0.05)$ & $0.02(0.06)$ & $-0.04 * * *(0.01)$ \\
\hline \multicolumn{4}{|c|}{ Main agricultural business (base category $=$ Specialist field crops) } \\
\hline Specialist horticulture & $0.24(0.12)$ & $0.24 *(0.12)$ & $-0.02(0.04)$ \\
\hline Specialist permanent crops & $0.26^{* *}(0.09)$ & $0.23 * *(0.09)$ & $0.01(0.07)$ \\
\hline Specialist ruminant livestock & $-0.03(0.20)$ & $-0.08(0.16)$ & $-0.04(0.07)$ \\
\hline Specialist granivore & $0.35(0.20)$ & $0.21(0.29)$ & $0.01(0.04)$ \\
\hline Mixed cropping & $0.05(0.17)$ & $-0.02(0.17)$ & $0.03(0.07)$ \\
\hline Mixed livestock & $0.06(0.31)$ & $-0.02(0.24)$ & $-0.00(0.11)$ \\
\hline Mixed crop-livestock & $0.11(0.15)$ & $0.02(0.15)$ & $0.03(0.04)$ \\
\hline Num. obs & 608 & 604 & 592 \\
\hline Log likelihood & -341.26 & -326.87 & -214.06 \\
\hline Deviance & 682.52 & 653.75 & 428.11 \\
\hline AIC & 746.52 & 717.75 & 492.11 \\
\hline BIC & 887.65 & 858.66 & 632.38 \\
\hline
\end{tabular}

$* * * \mathrm{p}<0.001, * * \mathrm{p}<0.01, * \mathrm{p}<0.05$ 


\section{References}

Agroscope. (2000). Neue methodik für die zentrale auswertung von Buchhaltungsdaten an der FAT [New methodology for the central evaluation of accounting data at the FAT]. Working Paper.

Agroscope. (2019). Schweiz bewilligt Sprühdrohnen als erstes Land Europas [Switzerland approves spray drones as the first country in Europe]. Retireved 25 July, 2019, from https://www.agroscope.admin.ch/ agroscope/de/home/aktuell/medieninformationen/medienmitteilungen.html.

ASVP, \& AIS. (2014). Fakten zum Schweizer Gemüsebau [Facts about Swiss vegetable growing]. Retireved 25 July, 2019, from https://www.gemuese.ch/Ressourcen/PDF/Politik/CHGemuesebau_BROSC HURE_LID.PDF.

Barnes, A., Soto, I., Eory, V., Beck, B., Balafoutis, A., Sánchez, B., et al. (2019). Exploring the adoption of precision agricultural technologies: A cross regional study of EU farmers. Land Use Policy, 80, 163-174.

Batte, M. T., \& Arnholt, M. W. (2003). Precision farming adoption and use in Ohio: Case studies of six leading-edge adopters. Computers and Electronics in Agriculture, 38(2), 125-139.

Cao, Q., Cui, Z., Chen, X., Khosla, R., Dao, T. H., \& Miao, Y. (2012). Quantifying spatial variability of indigenous nitrogen supply for precision nitrogen management in small scale farming. Precision Agriculture, 13(1), 45-61.

Coquil, B., Bordes, J. P., \& Stafford, J. (2005). FARMSTAR: An efficient decision support tool for near real time crop management from satellite images. In Precision agriculture'05 (pp. 873-880). Wageningen: Wageningen Academic Publishers.

Daberkow, S. G., \& McBride, W. D. (2003). Farm and operator characteristics affecting the awareness and adoption of precision agriculture technologies in the US. Precision Agriculture, 4(2), 163-177.

Ferjani, A., Zimmermann, A., \& Roesch, A. (2015). Determining factors of farm exit in agriculture in Switzerland. Agricultural Economics Review, 16(389), 59.

Finger, R., Swinton, S. M., Benni, N. E., \& Walter, A. (2019). Precision farming at the nexus of agricultural production and the environment. Annual Review of Resource Economics, 11, 313-335.

FOAG. (1999). Landwirtschaftliche Zonen-Verordnung [Agricultural zones regulation]. Retireved 25 July, 2019, from https://www.admin.ch/opc/de/classified-compilation/19983417/index.html.

FOAG. (2016). Charta zur digitalisierung der schweizer land- und ernährungswirtschaft [Charter for digitialisation in the agricultural and food sector]. Retireved 14 May, 2019, from https://www.blw.admin .ch/blw/de/home/services/medienmitteilungen.msg-id-71171.html.

FOAG. (2018). Agrarbericht [Agricultural report].

FOAG. (2019). Landwirtschaftsbetriebe: Grösse, Fläche, Besitzverhältnisse [Agricultural farms: size, area, ownership]. Retireved 25 July, 2019 from https://www.bfs.admin.ch/bfs/de/home/statistiken/land-forst wirtschaft.assetdetail.8346709.html.

FOCA. (2019). Faktenblatt Ausbringen aus der Luft mittels Drohnen [Fact sheet spreading from the air by means of drones]. Retireved 25 July, 2019, from https://www.bazl.admin.ch/bazl/de/home/suche .html\#Faktenblatt.

FSO. (2016). Strukturdatenerhebung [Farm structure survey]. Retireved 25 July, 2019, from https://www. bfs.admin.ch/bfs/de/home/statistiken/land-forstwirtschaft/erhebungen/stru.html.

FSO. (2017). Land- und Forstwirtschaft: Panorama [Statistical basis and overviews - Agriculture and forestry]. Retireved 25 July, 2019, from https://www.bfs.admin.ch/bfs/en/home/statistics/agriculture-fores try.assetdetail.7846585.html.

FSO. (2018a). Landwirtschaft und ernährung: Taschenstatistik [Agriculture and food: pocket statistics]. Retireved 25 July, 2019, from https:/www.bfs.admin.ch/bfs/de/home/statistiken/kataloge-datenbanke n/publikationen.assetdetail.5287762.html.

FSO. (2018b). Strassenfahrzeugbestand nach fahrzeuggruppe und fahrzeugart [Distribution of road vehicles]. Retireved 25 July, 2019, from https://www.bfs.admin.ch/bfs/de/home/statistiken/mobilitaet-verke hr/verkehrsinfrastruktur-fahrzeuge/fahrzeuge/strassenfahrzeuge-bestand-motorisierungsgrad.assetdetai 1.7226314.html.

Gebbers, R., \& Adamchuk, V. I. (2010). Precision agriculture and food security. Science, 327(5967), $828-831$.

Giles, D. K. (2016). Use of remotely piloted aircraft for pesticide applications: Issues and outlook. Outlooks on Pest Management, 27(5), 213-216.

Greene, W. H. (2018). Econometric analysis. London: Pearson Education. 
Heege, H. J. (2013). Site-specific fertilizing. In H. J. Heege (Ed.), Precision in crop farming: Site specific concepts and sensing methods: Applications and results (pp. 193-271). Dordrecht: Springer.

ISPA. (2019). ISPA precision Ag definition. Retireved 26 February, 2020, from https://ispag.org/.

King, A. (2017). The future of agriculture. Nature, 544(7651), S21-S23.

Konrad, M. T., Nielsen, H. Ø., Pedersen, A. B., \& Elofsson, K. (2019). Drivers of farmers' investments in nutrient abatement technologies in five Baltic Sea countries. Ecological Economics, 159, 91-100.

Lawson, L. G., Pedersen, S. M., Sørensen, C. G., Pesonen, L., Fountas, S., Werner, A., et al. (2011). A four nation survey of farm information management and advanced farming systems: A descriptive analysis of survey responses. Computers and Electronics in Agriculture, 77(1), 7-20.

Lowenberg-DeBoer, J., \& Erickson, B. (2019). How does European adoption of precision agriculture compare to worldwide trends? In Precision agriculture'19 (pp. 7-20). Wageningen: Wageningen Academic Publishers.

Matese, A., Toscano, P., Di Gennaro, S., Genesio, L., Vaccari, F., Primicerio, J., et al. (2015). Intercomparison of UAV, aircraft and satellite remote sensing platforms for precision viticulture. Remote Sensing, 7(3), 2971-2990.

McBride, W. D., \& Daberkow, S. G. (2003). Information and the adoption of precision farming technologies. Journal of Agribusiness, 21(1), 21-38.

Miller, N. J., Griffin, T. W., Ciampitti, I. A., \& Sharda, A. (2019). Farm adoption of embodied knowledge and information intensive precision agriculture technology bundles. Precision Agriculture, 20(2), $348-361$.

Mulla, D. J. (2013). Twenty five years of remote sensing in precision agriculture: Key advances and remaining knowledge gaps. Biosystems Engineering, 114(4), 358-371.

Paustian, M., \& Theuvsen, L. (2017). Adoption of precision agriculture technologies by German crop farmers. Precision Agriculture, 18(5), 701-716.

Pierpaoli, E., Carli, G., Pignatti, E., \& Canavari, M. (2013). Drivers of precision agriculture technologies adoption: A literature review. Procedia Technology, 8, 61-69.

Pongnumkul, S., Chaovalit, P., \& Surasvadi, N. (2015). Applications of smartphone-based sensors in agriculture: A systematic review of research. Journal of Sensors, 2015, 1-18.

Reichardt, M., \& Jürgens, C. (2009). Adoption and future perspective of precision farming in Germany: Results of several surveys among different agricultural target groups. Precision Agriculture, 10(1), 73-94.

Roldán, J. J., del Cerro, J., Garzón-Ramos, D., Garcia-Aunon, P., Garzón, M., de León, J., et al. (2017). Robots in agriculture: State of art and practical experiences. In Service robots. London: IntechOpen.

Schimmelpfennig, D. (2016). Farm profits and adoption of precision agriculture (No. 1477-2016-121190).

Schimmelpfennig, D. (2018). Crop production costs, profits, and ecosystem stewardship with precision agriculture. Journal of Agricultural and Applied Economics, 50(1), 81-103.

Santesteban, L., Di Gennaro, S., Herrero-Langreo, A., Miranda, C., Royo, J., \& Matese, A. (2017). Highresolution UAV-based thermal imaging to estimate the instantaneous and seasonal variability of plant water status within a vineyard. Agricultural Water Management, 183, 49-59.

SATW. (2019). Drones in precision farming. Retireved 25 July, 2019, from https://www.satw.ch/en/early -identification/technologies/details/technology/drones-in-precision-farming/.

Shepherd, M., Turner, J. A., Small, B., \& Wheeler, D. (2018). Priorities for science to overcome hurdles thwarting the full promise of the 'digital agriculture'revolution. Journal of the Science of Food and Agriculture. https://doi.org/10.1002/jsfa.9346.

Soenen, B., Closset, M., Bonnard, A., \& Le Bris, X. (2017). Validation of a new nitrogen management tool on winter wheat based on remote sensing diagnostic and agronomic prognosis: 'QN-method'-FARMSTAR. In Proceedings of Innovative Solutions for Sustainable Nitrogen Management (pp. 32-33).

Tamirat, T. W., Pedersen, S. M., \& Lind, K. M. (2018). Farm and operator characteristics affecting adoption of precision agriculture in Denmark and Germany. Acta Agriculturae Scandinavica B, 68(4), 349-357.

$\mathrm{R}$ Core Team. (2013). R: A language and environment for statistical computing. Vienna: Austria.

Tey, Y. S., \& Brindal, M. (2012). Factors influencing the adoption of precision agricultural technologies: A review for policy implications. Precision Agriculture, 13(6), 713-730.

Walter, A., Finger, R., Huber, R., \& Buchmann, N. (2017). Opinion: Smart farming is key to developing sustainable agriculture. Proceedings of the National Academy of Sciences, 114(24), 6148-6150.

Winstead, A. T., Norwood, S. H., Griffin, T. W., Runge, M., Adrian, A. M., Fulton, J., et al. (2010). Adoption and use of precision agriculture technologies by practitioners. In Proceedings of the 10th International Conference on Precision Agriculture (pp. 18-21). 
Xiongkui, H., Bonds, J., Herbst, A., \& Langenakens, J. (2017). Recent development of unmanned aerial vehicle for plant protection in East Asia. International Journal of Agricultural and Biological Engineering, 10(3), 18-30.

Zhang, N., Wang, M., \& Wang, N. (2002). Precision agriculture: A worldwide overview. Computers and Electronics in Agriculture, 36(2-3), 113-132.

Publisher's Note Springer Nature remains neutral with regard to jurisdictional claims in published maps and institutional affiliations. 